\title{
Strength and Wear Behavior of Mg Alloy AE42 Reinforced with Carbon Short Fibers
}

\author{
Sabbah Ataya ${ }^{1,2} \cdot$ Naser A. Alsaleh ${ }^{2} \cdot$ Mohamed M. El-Sayed Seleman ${ }^{1}$ \\ Received: 28 March 2018/Revised: 9 May 2018/Published online: 22 June 2018 \\ (C) The Chinese Society for Metals and Springer-Verlag GmbH Germany, part of Springer Nature 2018
}

\begin{abstract}
In addition to the advantage of the lightweight of magnesium alloys, magnesium composites have moderate strength and elastic modulus. The proposed application of magnesium composites as diesel truck pistons makes it necessary to assess their wear performance. Little research data have been discussed on wear behavior of Mg alloy AE42 matrix and its composites. Thus, this paper reports wear behavior of magnesium alloy AE42 (Mg-Al-Mn-RE; rare earth) and its composite AE42-C, which contains $23 \mathrm{vol} \%$ of randomly oriented carbon short fibers. Materials characterization, including density measurements, hardness testing, microstructures investigation, and compression testing at temperatures of 25, 150, and $300{ }^{\circ} \mathrm{C}$, were conducted. Wear tests were performed under various loads and sliding distances. Wear mechanisms were also proposed based on the examination of worn surfaces using optical microscopy and scanning electron microscopy equipped with EDX (energy-dispersive X-ray spectrometry) analysis system. The hardness of AE42-23 vol\% C composite is twice the hardness of the $\mathrm{Mg}$ matrix alloy AE42. Significant improvements to yield stress and compressive strength at temperatures of 25,150 , and $300{ }^{\circ} \mathrm{C}$ of the composite versus the AE42 alloy are achieved. Wear resistance of the composite is improved considerably versus that of the Mg alloy AE42 at the various sliding distances. Smearing of graphite on the worn surface produces a lubricating film that delays change from mild to severe wear of the composite, especially at high loads. EDX analysis of the worn surface shows oxidation of the matrix alloy at higher wear loads, and this mechanism decreases in the presence of carbon fibers under the same loads. Abrasive wear, oxidation, and plastic deformation are the dominant wear mechanisms for the alloy matrix AE42, whereas mainly abrasive wear is the wear mechanism of AE4223 vol\% C composite under the proposed testing conditions.
\end{abstract}

Keywords Magnesium composites · Carbon short fibers · Compressive strength $\cdot$ Wear resistance $\cdot$ Wear mechanisms

\section{Introduction}

The high strength-to-weight ratio of magnesium alloys makes them attractive for structural applications in aerospace, automotive, electronic, and biomedical industries. However, magnesium has low elastic modulus (45 GPa),

Available online at http://link.springer.com/journal/40195.

Sabbah Ataya

sabbah.ataya@suezuniv.edu.eg

1 Metallurgical and Materials Engineering Department, Faculty of Petroleum and Mining Engineering, Suez University, Suez 43721, Egypt

2 Department of Mechanical Engineering, College of Engineering, Al Imam Mohammad Ibn Saud University, Riyadh 11432, Saudi Arabia and low fatigue, creep [1], and corrosion resistance [2]. Recently, new materials are required to fill increasing demands for high-temperature performance of light metals. Many studies demonstrated that the mechanical properties and stability of magnesium alloys at elevated temperatures can be enhanced with incorporating reinforcing materials to produce composites [3, 4]. Reinforcement of $\mathrm{Mg}$ alloys using short fibers of $\mathrm{Al}_{2} \mathrm{O}_{3}$ [5] or carbon improves mechanical strength [6,7] and creep resistance [8]. It is economically viable to use carbon short fibers instead of continuous fibers as a reinforcing phase to fabricate composites due to ease of production, keeping advantage of lightweight and the significant improvement in mechanical properties [6]. Strength improvement was reached $127 \%$ compared with the matrix alloy (AE44), while Young's module enhanced by 74\% [9].

Reinforcing magnesium alloys AE42 and AZ91 with 23 vol\% oriented carbon fibers (parallel or normal) to the 
direction of an applied load significantly increases hightemperature strength [10] and creep resistance in comparison with unreinforced magnesium alloys [8]. Magnesium alloys can be reinforced using higher percentages (50-60 vol\%) of either fine-woven or unidirectional carbon fibers to achieve greater mechanical strength and elastic modulus [1]. Attention has been paid to $\mathrm{Mg}-\mathrm{Al}$ alloy (AE42) as a good recommended matrix to fabricate composites. This alloy is widely applied in the $\mathrm{Mg}-\mathrm{Al}-\mathrm{RE}$ family due to its low-cost, enhanced creep resistance [8], moderate fatigue strength [11], and improved thermal conductivity [12]. Adding of $1 \mathrm{vol} \%$ $\mathrm{Ni}$-coated carbon short fiber to magnesium by powder metallurgy has been increased the strength and thermal conductivity [13]. Reinforcing Mg alloys with a strengthening agent, such as particulates or fibers in micro- or nanosizes, resulted in significant improvements to high-temperature strength [14], creep [15], and wear resistance [16].

Wear characteristics of magnesium alloy AZ31 reinforced with small amounts (up to $1.50 \mathrm{vol} \%$ ) alumina nanoparticulates have been studied [16]. Abrasion, oxidation, adhesion, delamination, thermal softening, and melting were reported as the dominant wear mechanisms of the composite at various sliding speeds [16]. The mechanical properties and wear resistance of $\mathrm{Mg}$ nanocomposite containing 3 vol\% carbon nanotubes were higher in comparison with AZ91D Mg alloy matrix [17]. The wear rate improvement of the $\mathrm{Mg}-\mathrm{SiC}_{p}$ composites over the $\mathrm{Mg}$ pure matrix was obtained with increasing $\mathrm{SiC}$ particles content [14]. Graphite provides a lubrication film to the worn surface of the alloy and then increases wear resistance besides increasing the materials strength [18]. The wear behavior of AE42 that is reinforced with $20 \% \mathrm{Al}_{2} \mathrm{O}_{3}$ short fibers was studied by Mondal et al. [19], which might have different wear behaviors from carbon short fibers. Moreover, Olszówka-Myalska and Myalski [20] concluded that the lubrication effect on wear of the magnesium alloys reinforced with carbon fibers still needs further studies. Thus, there is still an urgent demand to improve knowledge about the wear behavior of $\mathrm{Mg}$ alloy AE42 matrix-graphite composites. Based on potential applications, such as truck pistons, it is important to study the wear characteristics of a composite based on $\mathrm{Mg}$ alloy $\mathrm{AE} 42$ that is reinforced with $23 \mathrm{vol} \%$ randomly oriented carbon short fibers. Thereto, the current study investigates mechanical properties and wear behaviors of Mg alloy AE42 and its composite (AE42-C).

\section{Experimental Procedures}

\subsection{Starting Materials}

The starting material was a magnesium-based composite (AE42-C). This composite was fabricated by strengthening magnesium alloy AE42 with 23 vol\% randomly oriented carbon short fibers using a squeeze-casting technique [21]. Carbon fibers were manufactured by SGL carbon and produced from polyacrylonitrile (PAN). The carbon fibers were surface-treated [22] to improve poor wettability between carbon fibers and magnesium alloy melt. Fiber lengths and diameters were 80-120 and 5-6 $\mu \mathrm{m}$, respectively. For comparison, cast magnesium alloy AE42 was also produced using the same process. Tested materials (AE42 and AE42-C) were supplied in the form of cast blocks from Kolbenschmidt Company, Neckarsulm, Germany. Table 1 shows the nominal chemical composition of AE42, where the main alloying elements are $\mathrm{Al}$ and $\mathrm{Mn}$ and the rare earth (RE) elements are $\mathrm{Ce}, \mathrm{La}, \mathrm{Nd}, \mathrm{Pr}$, and Th. Table 2 shows the physico-mechanical properties of the carbon short fibers.

\subsection{Characterization of the AE42 and AE42-C Composite}

The AE42 alloy and AE42-C composite were machined into cylindrical specimens of $6 \mathrm{~mm}$ in diameter $(D)$ and $8 \mathrm{~mm}$ height $(H)$. The densities of the as-cast specimens were measured using Archimedes' principle in toluene. The theoretical density was also determined based on the rule of mixture. Hardness was measured with a Vickers Hardness Tester Model HWDV-7S using a load of $2 \mathrm{~kg}$ and a holding time of $15 \mathrm{~s}$. The hardness value was taken as the average of 8 readings. Compression test was conducted at different temperatures of 25,150 , and $300{ }^{\circ} \mathrm{C}$, using the machined cylindrical specimens. The specimens geometry meets the requirements of compression specimens $(H \leq 1.5 D)$ to avoid bucking during loading. The compression test was performed at the usual quasi-static testing strain rate of $0.001 \mathrm{~s}^{-1}$ using a universal testing machine type Instron 4208 equipped with additionally installed heating furnace (up to $750 \pm 3{ }^{\circ} \mathrm{C}$ ). Wear testing of the AE42 alloy base material and AE42-C short carbon fibers composite under dry conditions was conducted on a pin-on-bush machine as shown in Fig. 1. The sliding counterface (bush) was made of $58 \mathrm{HRC}$ hard steel. The bush width was $45 \mathrm{~mm}$. The bush was fine ground by SiC paper grit 800 and cleaned before the test to remove any residuals from the previous run. New test sample was used for each run, and the test surface was ground by $\mathrm{SiC}$ paper grit 800 too. The first group of AE42 alloys and the

Table 1 Chemical composition (wt\%) of magnesium matrix material (AE42)

\begin{tabular}{lllllllll}
\hline $\mathrm{Al}$ & $\mathrm{Zn}$ & $\mathrm{Mn}$ & $\mathrm{Ce}$ & $\mathrm{La}$ & $\mathrm{Nd}$ & $\mathrm{Pr}$ & $\mathrm{Th}$ & $\mathrm{Mg}$ \\
\hline 3.93 & 0.01 & 0.30 & 1.20 & 0.60 & 0.40 & 0.10 & 0.26 & Bal. \\
\hline
\end{tabular}


Table 2 Nominal chemical composition and physico-mechanical properties of the carbon short fibers [23]

\begin{tabular}{lllll}
\hline Nominal composition $(\mathrm{wt} \%)$ & Density $\left(\mathrm{g} / \mathrm{cm}^{3}\right)$ & Tensile strength $(\mathrm{GPa})$ & Elastic modulus $(\mathrm{GPa})$ & Strain to failure $(\%)$ \\
\hline$>95 \mathrm{C}$ & 1.76 & $2-3.5$ & $230-400$ & $1.2-1.5$ \\
\hline
\end{tabular}

composite specimens were tested at a constant running time of $10 \mathrm{~min}$ (sliding distance of $8.92 \mathrm{~km}$ ) using various loads of 2.45, 4.9, 7.35, and $9.81 \mathrm{~N}$. Based on the result of the examined first group, a constant moderate load of $3.14 \mathrm{~N}$ was used to test the second group of specimens under running times of $10,20,30$, and 40 min (i.e., 8.92, $17.84,26.77$, and $35.69 \mathrm{~km}$ ). Weight loss due to wear on the pins was measured using a digital balance, with accuracy of $\pm 0.01 \mathrm{mg}$. Each wear experiment was repeated at least four times to ensure repeatability of results. Microstructure observations of the polished surfaces, and worn surfaces of the $\mathrm{Mg}$ matrix alloy and the AE42-C composite, were investigated using an optical microscope (Kruess MMB-2200) and scanning electron microscope (SEM, Quanta FEG 250), equipped with an energy-dispersive X-ray spectrometry (EDX) analysis system.

\section{Results and Discussion}

\subsection{Density and Hardness Results}

The density and hardness of the Mg alloy AE42 and Mg alloy AE42-C composite are shown in Table 3. The relative density is referring the measured bulk density to the theoretical density. For the matrix, the theoretical density is $1.80 \mathrm{~g} / \mathrm{cm}^{3}$ [24], and for the composite it is calculated using the rule of mixture from the density value of the base alloy and the reinforcing fibers $\left(1.76 \mathrm{~g} / \mathrm{cm}^{3}\right)$ [24]. The AE42-C composite has a higher relative density than the AE42 alloy. The hardness of AE42 Mg alloy increased by $100 \%$ with the addition of 23 vol\% random carbon short fibers. This increase in hardness reveals the reinforcing

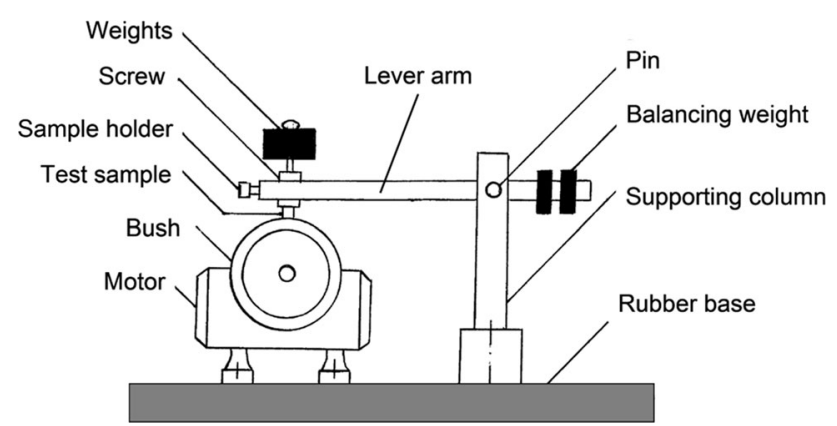

Fig. 1 Pin-on-bush wear testing machine effectiveness of the high volume content of carbon fibers. Addition of only $7 \mathrm{vol} \%$ carbon short fibers to the Mg alloy AZ91 [20] has led to an increase in the hardness value by $22 \%$ of the matrix hardness.

\subsection{Microstructural Observations}

Optical microstructures of the matrix alloy AE42 and AE42-23 vol\% carbon short fibers composite are shown in Fig. 2. The micrograph in Fig. 2a shows primarily irregular shaped cast primary magnesium grains. The size of grains is ranged from 15 to $25 \mu \mathrm{m}$. Fine eutectic lamellae are detected at the grain frontiers. The carbon short fibers (Fig. 2b) are nearly uniformly distributed in the magnesium matrix alloy without any residual microporosity and fibers breakage. This can explain and confirm bulk density measurements (Table 3). Furthermore, the increase in relative density of the composite over the matrix material can be ascribed to efficiency of the squeeze-casting technique to produce porosity free castings. The reinforcement phase remains well bonded to the matrix, and no obvious casting defects are detected. Finally, the fabrication technique produced nearly full-density composite materials of the AE42 matrix alloy with a high volume (23 vol\%) of random carbon short fibers. No grain boundaries are revealed in the composite material.

\subsection{Compression Test Results}

It is important to examine the behavior of the studied materials under compressive loading, which is more relevant to wear load. The nominal compression stress-strain curves of the matrix (AE42) and the composite (AE42-C) at various temperatures are shown in Fig. 3, and the gained compression test results are plotted in Fig. 4. It can be seen that in the temperature range from room temperature $(R T=25)$ to $300{ }^{\circ} \mathrm{C}$, the yield stress and compressive strength of the AE42-C composite are higher than that for the AE42 alloy. Such improvements in mechanical properties of the composite versus the AE42 alloy can be attributed to the high modulus of elasticity of the carbon short fibers, which are bonded well to the AE42 alloy matrix. These results are in agreement with that reported by $\mathrm{Li}$ et al. [9] for AE44 Mg alloy reinforced with carbon fibers. Both AE42 alloy matrix and AE42-C composite exhibit nearly the same value of fracture strain at RT and 
Table 3 Density and hardness of Mg alloy AE42 and its composite AE42-C

\begin{tabular}{lllll}
\hline Material & Theoretical density $\left(\mathrm{g} / \mathrm{cm}^{3}\right)$ & Bulk density $\left(\mathrm{g} / \mathrm{cm}^{3}\right)$ & Relative density $(\%)$ & Hardness $(\mathrm{HV})$ \\
\hline AE42 alloy & 1.80 & 1.69 & 94 & 46.8 \\
AE42-23 vol\% C & 1.79 & 1.72 & 96 & 91.2 \\
\hline
\end{tabular}
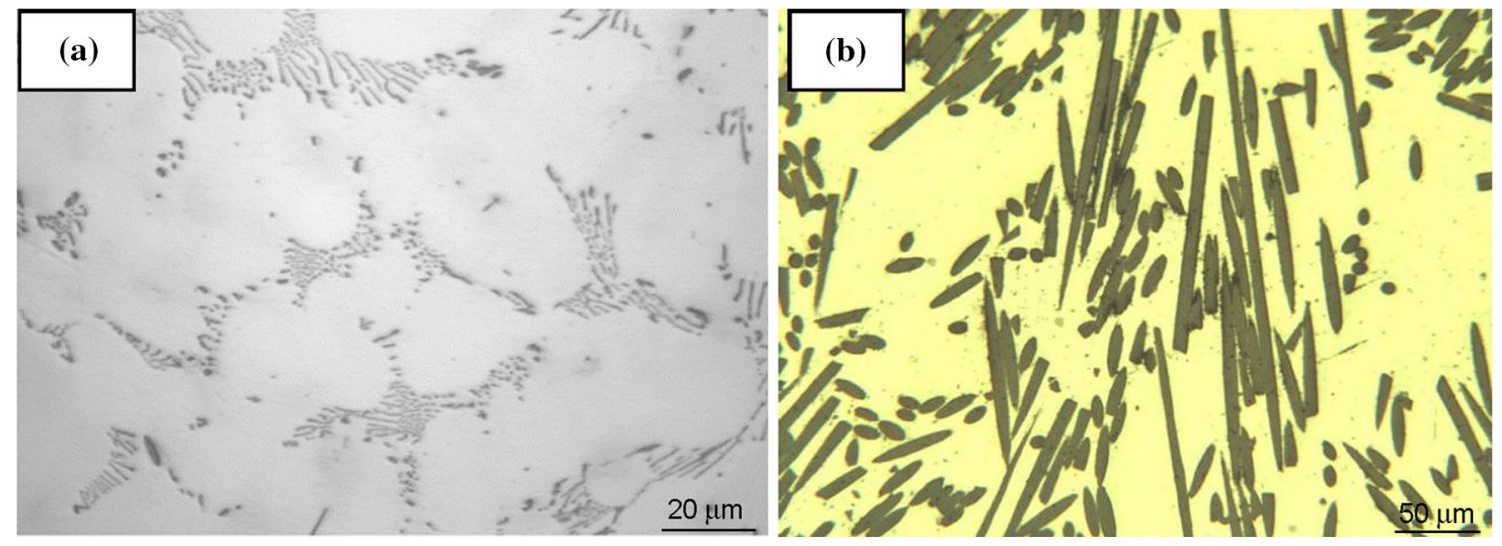

Fig. 2 Optical microstructure images of a Mg alloy AE42, b AE42-C composite
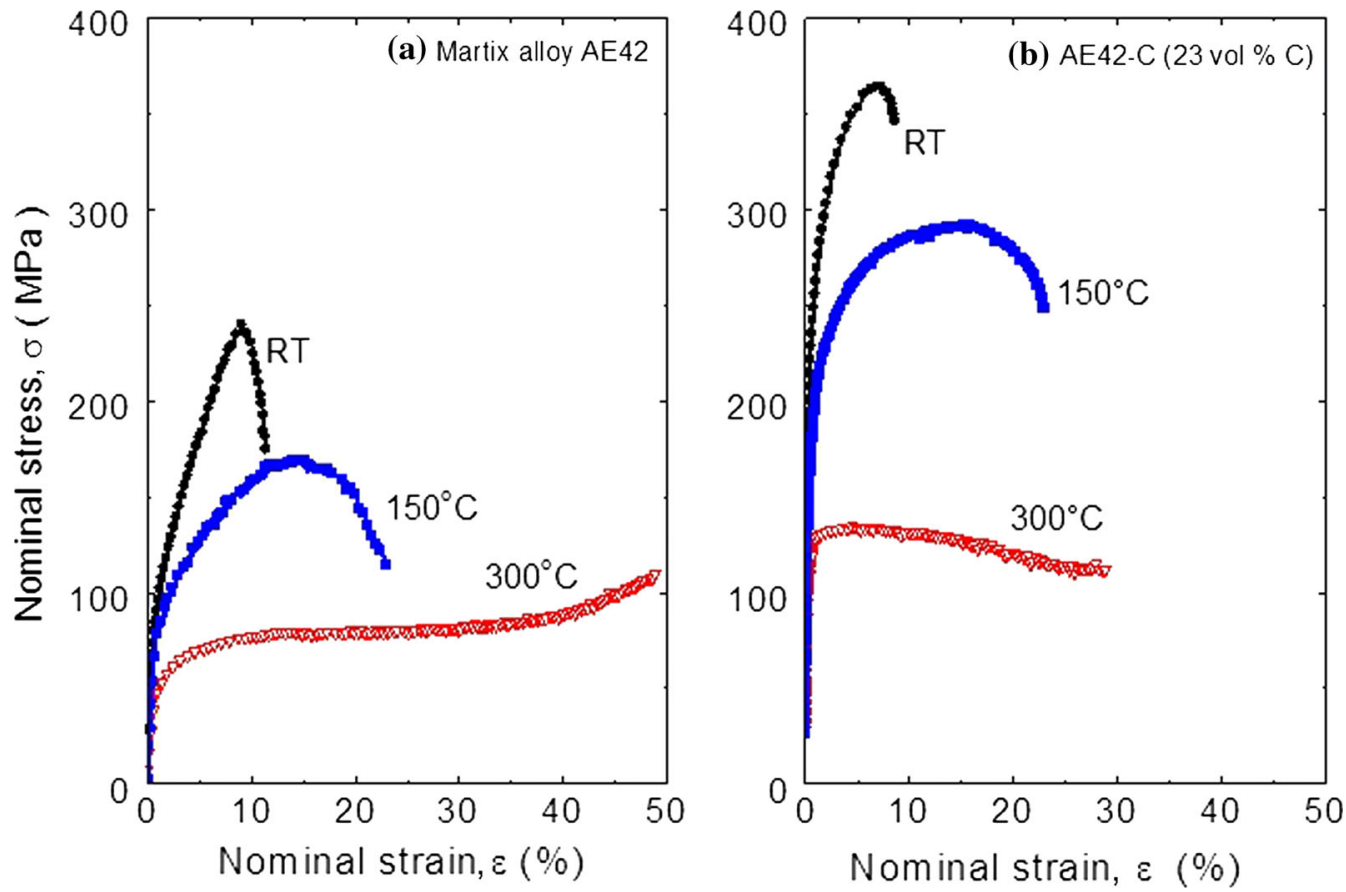

Fig. 3 Nominal stress strain curves of a AE42, b AE42-C

$150{ }^{\circ} \mathrm{C}$ due to the brittle nature of magnesium alloys that have a hexagonal crystal structure, whereas at a higher temperature $\left(300{ }^{\circ} \mathrm{C}\right)$, the fracture strain of the magnesium alloy is much higher than that of the composite due to the softening effect of the temperature on the plastic deformation of the matrix alloy. The presence of the elastic bodies (graphite fibers) in the composite material limits continual plastic deformation of the composite at this temperature.

\subsection{Wear Test Results}

The AE42-C composite is suggested to be used as an antiwear material due to the presence of a solid graphite 

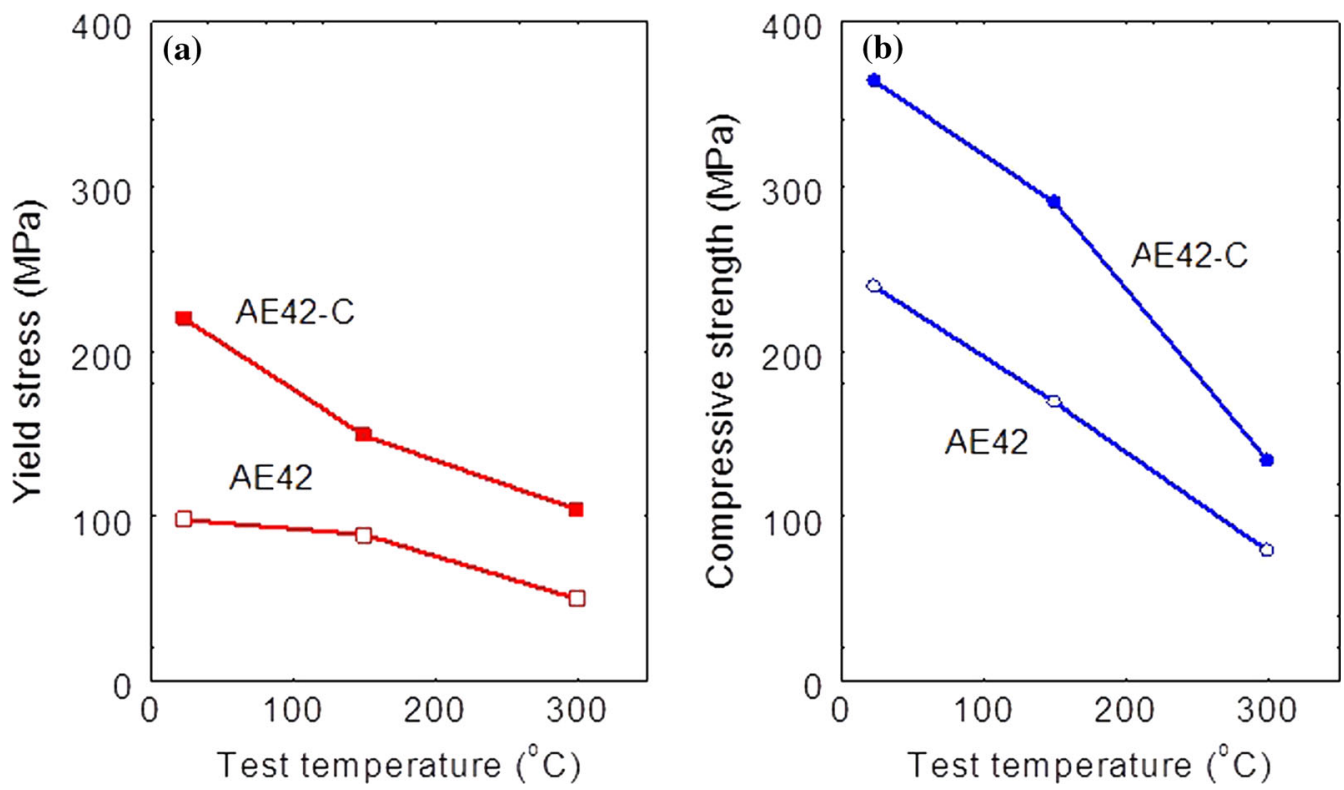

Fig. 4 Compression test results at various test temperatures for AE42 and AE42-C: a compressive yield stress, b compressive strength

lubricant, which is known to improve wear resistance when applied to sliding surfaces. It is therefore important to examine the wear behavior of such a composite in comparison with the base AE42 alloy. The first group of wear tests was conducted for a distance of $8.92 \mathrm{~km}$ using various loads of 2.45, 4.9, 7.35, and 9.81 $\mathrm{N}$ for both the $\mathrm{Mg}$ alloy AE42 and Mg alloy AE42-C composite. Figure 5 displays weight loss against applied wear load for $\mathrm{Mg}$ alloy AE42 and its composite AE42-C, which contains 23 vol\% carbon short fibers. The weight loss of the matrix alloy AE42 is higher than that of its composite for all wear loads. It is also shown that the weight loss increased with increasing loads for both the matrix alloy and the composite material over the running distance $(8.92 \mathrm{~km})$. In order to analyze the wear performance of the Mg alloy AE42 base material and

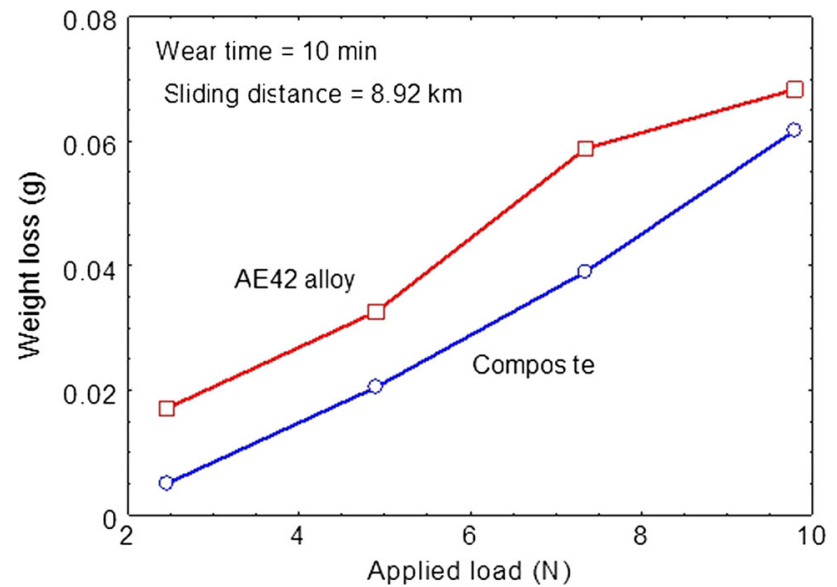

Fig. 5 Weight loss versus applied wear load for Mg alloy AE42 and its composite AE42-C, which contains 23 vol\% carbon short fibers
AE42-C composite at various sliding distances, the second group of wear tests was conducted under a constant mild load of $3.14 \mathrm{~N}$ using various wear distances of 8.92, 17.84, 26.77, and $35.69 \mathrm{~km}$. This load (3.14 N) was selected based on the results of the first group experiments to be lying in mild wear region and away from the severe wear stage. As shown in Fig. 6, the wear resistance in terms of weight loss of $\mathrm{Mg}$ alloy $\mathrm{AE} 42$ does not increase monotonically as given by AE42-C composite with increasing sliding distances. Above $26.77 \mathrm{~km}$, the weight loss for AE42 base material increases sharply. This abrupt increase in material loss of the matrix can be attributed to beginning severe regime of wear. The brittle behavior and considerably low shear resistance of $\mathrm{Mg}$ alloy are responsible for the severe wear. This finding is consistent with the results

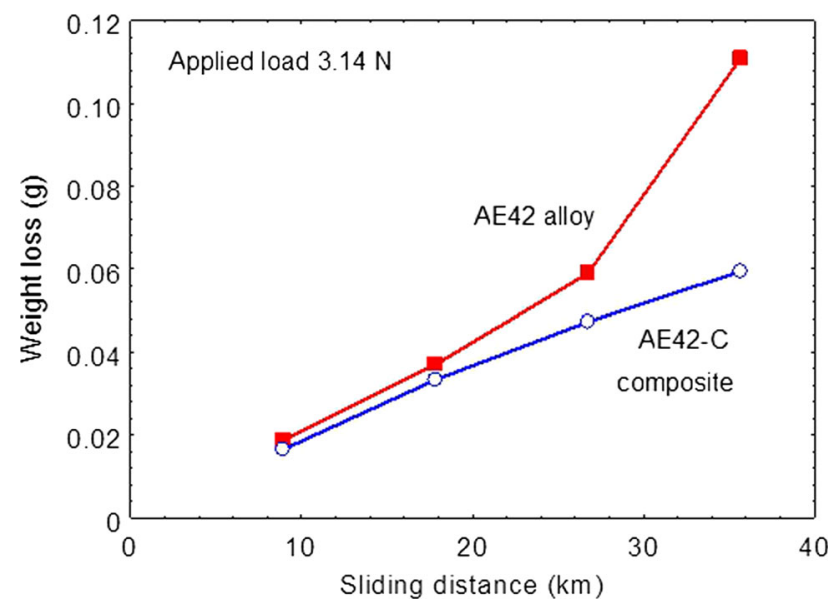

Fig. 6 Weight loss versus running distance for AE42 and AE42-C 
of other researchers $[14,17]$. From Fig. 6, for the Mg alloy $\mathrm{AE} 42$, there is no linear dependency on the running time of the wear test.

Consequently, it can be expected that more than one mode of wear mechanisms could be operated altogether to the AE42 alloy at higher sliding distances. The sudden change in the trend of weight loss for alloy AE42 is not observed in the composite (Fig. 6). This can be explained by operating mainly one mode of wear mechanism from the beginning to the end of test for the composite material. This behavior is due to the formation of a lubrication film of graphite between the AE42-C composite material and the hard surface of the steel bush, which will be explained later in the current study based on the microstructural investigation of the worn surfaces.

The average wear rate in terms of $\mathrm{mm}^{3} / \mathrm{m}$ for each test condition for both AE42 alloy and its composite, which contains $23 \mathrm{vol} \%$ graphite short fibers, at a constant load of $3.14 \mathrm{~N}$ is plotted as a function of sliding distance in Fig. 7. The figure shows that the wear rate of the base material is higher than that of the composite at various test distances from 8.92 to $35.67 \mathrm{~km}$. For example, at a sliding distance of up to $17.84 \mathrm{~km}$, the wear rate of the matrix alloy is higher than that of the composite by $25 \%$, but it reaches two times higher than that of the composite at a sliding distance of $35.67 \mathrm{~km}$. As shown also in Fig. 7, the wear rate of both materials is nearly linear up to $17.8 \mathrm{~km}$. At sliding distances higher than $17.8 \mathrm{~km}$, the wear rate of AE42 increases, while that of AE42-C decreases. Thus, it can be concluded that the wear resistance of AE42-C composite is higher than that of the AE42 matrix alloy. The presence of random graphite short fibers was beneficial for wear resistance at moderate and higher sliding distances. This conclusion is consistent with the wear behavior, which

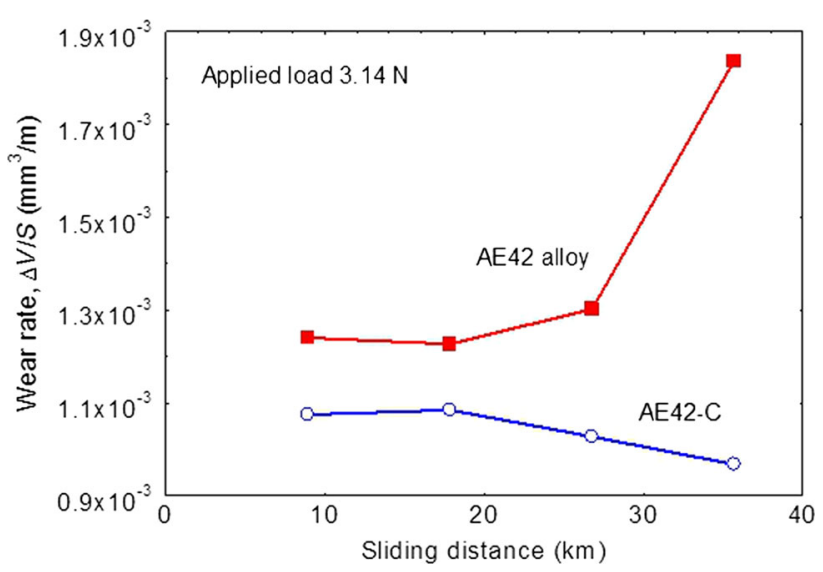

Fig. 7 Wear rate versus sliding distance for AE42 and AE42-C under a wear load of $3.14 \mathrm{~N}$ has been reported for various metal matrix composites reinforced with different graphite morphologies [14, 18].

\subsection{Worn Surface Investigation}

Worn surfaces of wear-tested base material AE42 under a moderate sliding distance of $8.92 \mathrm{~km}$, and wear load at $9.81 \mathrm{~N}$, are shown in Fig. 8. The loads were sufficient for surface damage. The worn surface of the base alloy shows clear damage in the form of continuous scratches. These parallel deep scratches indicate plastic deformation by the harder counterface of the bush. There are also small smooth regions interspersed with wear scars (Fig. 8b) and transverse micro-cracks (Fig. 8a). A notable feature in the micrographs is inclined shear plates, which indicates that asperities contact produced localized deformation (Fig. 8c, d), and the inclined shear plates could be due to high surface stress. At the lower wear load of $3.14 \mathrm{~N}$ (Fig. 9a), the worn surface has similar morphology to that under the higher wear load of $9.81 \mathrm{~N}$. Therefore, the width of the deep scratches increases with increasing wear load.

From the observed features on the worn surface, the principal wear mechanisms at the wear test of AE42 are abrasion and plastic deformation. This conclusion is supported by similar worn surface observations during previous studies on the dry-sliding wear of magnesium alloy AE42 [25]. The worn surface of graphite that contained composite material displayed other features (Figs. 9b, 10). At similar sliding distances and loads (Fig. 9), the scratches (plowing) in the composite become shallower than that in the matrix alloy due to the presence of graphite short fibers. However, the inclined shear plates nearly disappear from the affected surface of the composite material. Carbon fibers are subjected to fragmentation at the surface as shown in the white areas in Figs. 9b and 10b. Smearing the worn surface with graphite film is generally observed (Figs. 9b, 10). This film appears in the worn surface of AE42-C composite as the action of the abrasive wear and fragmentation of short carbon fibers. The graphite film lubricates the surface and decreases the effect of the abrasive friction and generally decreases the wear of the AE42-C composite. Thus, the mainly working wear mechanism of the AE42-C composite is likely to be abrasive wear. Mondal et al. [19] studied the wear behavior for AE42 alloy matrix and AE42-20\% saffil (delta- $\mathrm{Al}_{2} \mathrm{O}_{3}$ ) short fibers composite under different loads $(5-40 \mathrm{~N})$ and a constant sliding distance of $2.5 \mathrm{~km}$. They concluded that the composite showed better wear resistance up to a certain load, and after that, the wear resistance drastically decreased less than the AE42 matrix alloy. The presence of broken alumina fibers in between the sliding surfaces enhances the formation grooves. These plowing grooves 

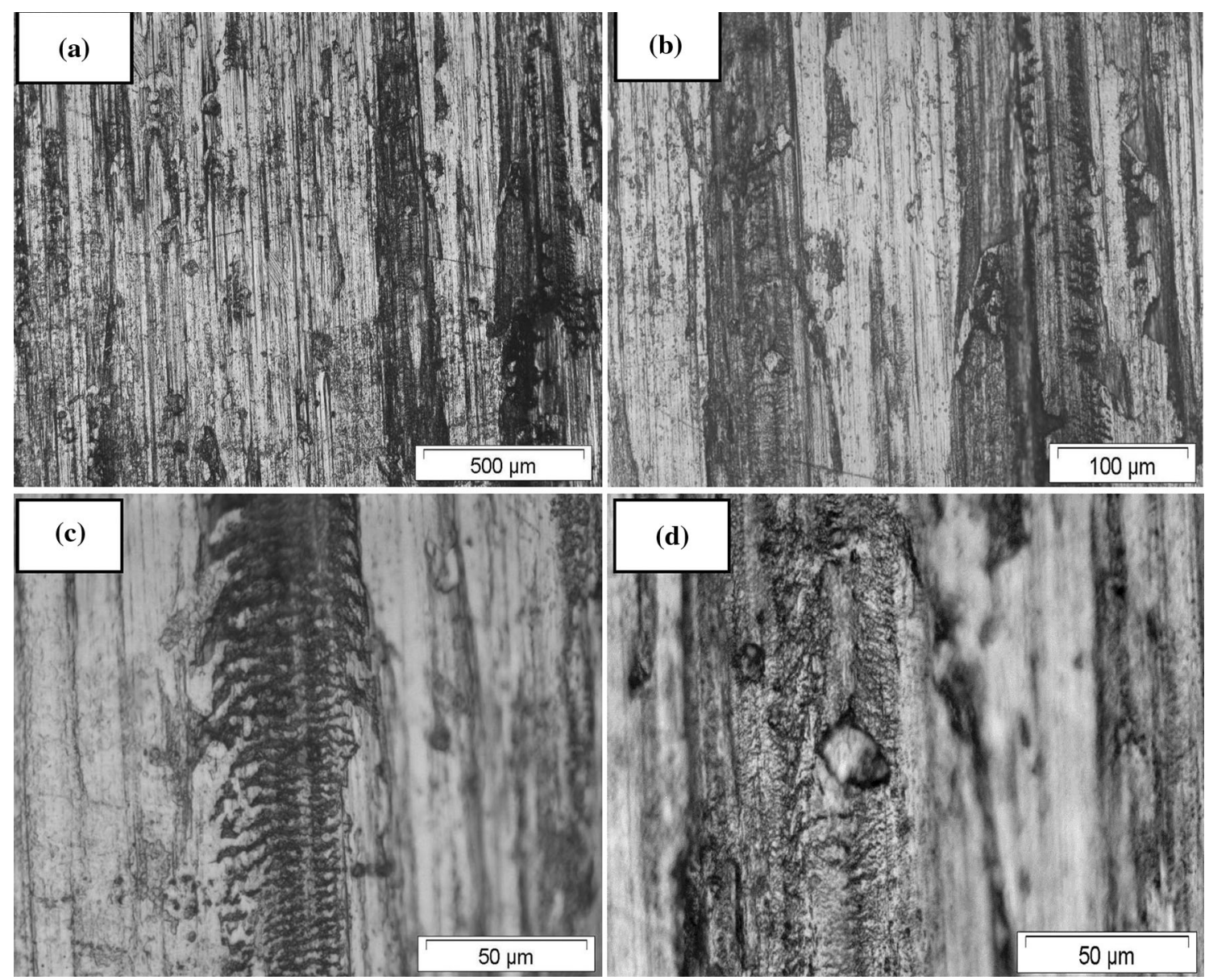

Fig. 8 Magnified worn surface of the AE42 alloy under wear load of $9.81 \mathrm{~N}$ and sliding distance of $8.92 \mathrm{~km}$
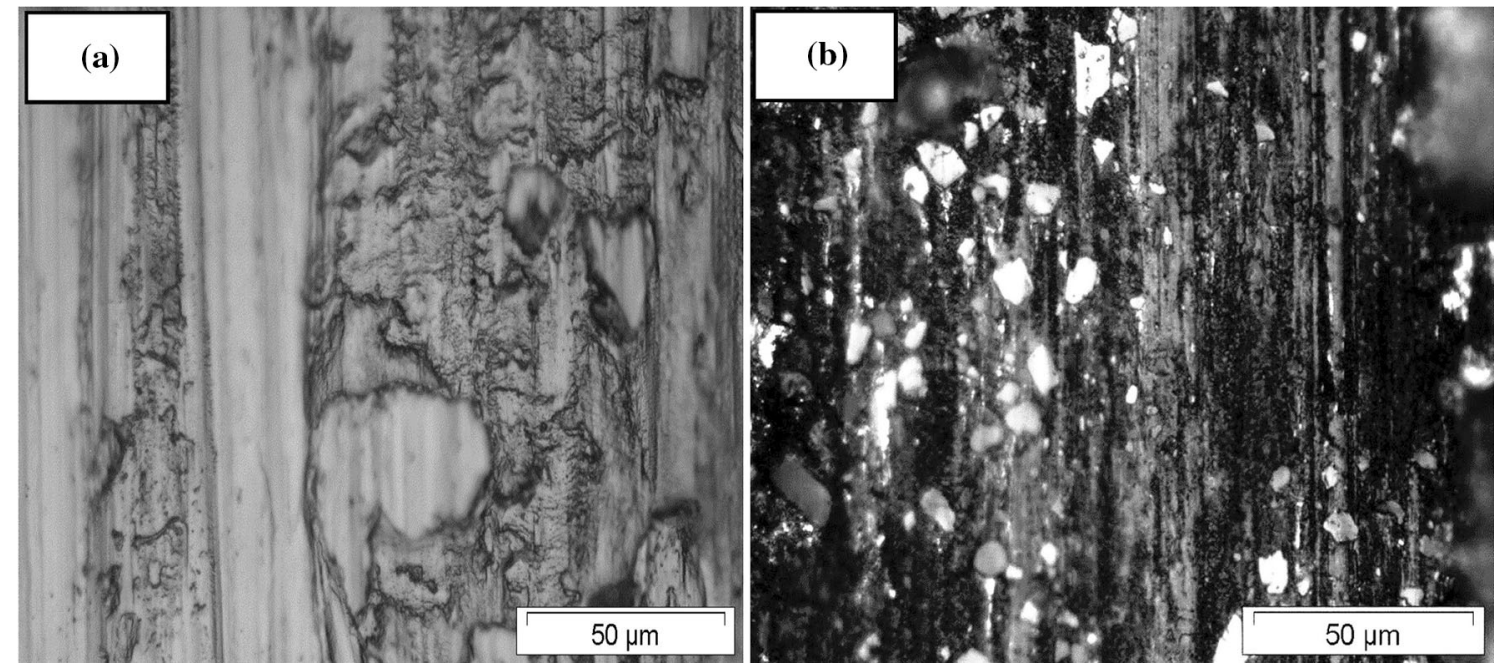

Fig. 9 Worn surface under a wear load of $3.14 \mathrm{~N}$ and sliding distance of $8.92 \mathrm{~km}$ : a AE42, b AE42-C

become larger and deeper at higher loads and speeds. Thus, the saffil short fiber does not prefer to be used in improving wear resistance of the AE42 for a high load application. In contrast, based on the current obtained results, the presence of the broken carbon short fibers between the sliding surfaces enhances the graphite film formation and then reduces the friction and despites heat. Consequently, it improves the wear resistance of AR42 at wide range of 

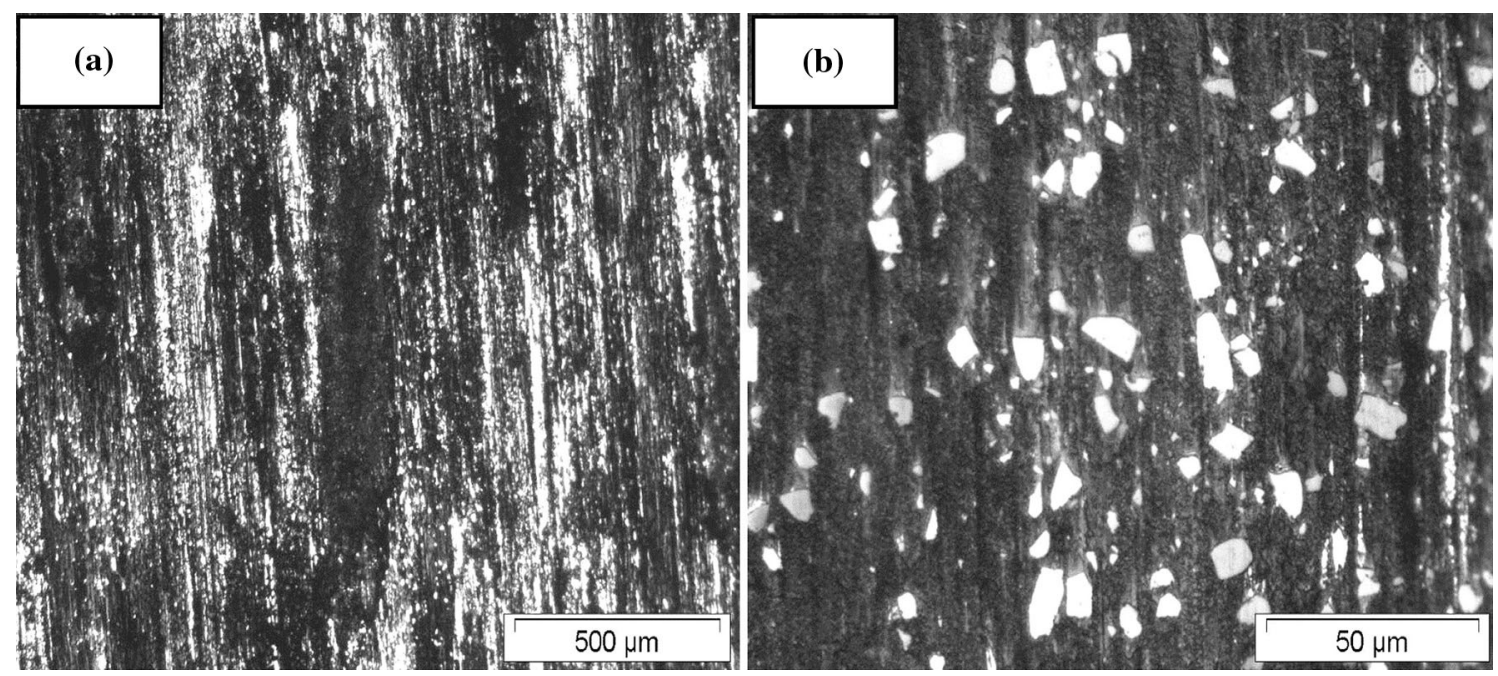

Fig. 10 a Worn surface of AE42-C under a wear load of $9.81 \mathrm{~N}$ and sliding distance of $8.92 \mathrm{~km}$, b higher magnification of a

loads. So that it can be recommended to incorporate random carbon short fibers up to 23 vol\% instead of random alumina short fibers up to 20 vol\%.

The outcome of sliding is complex for composite materials that contain solid lubricants such as random graphite short fibers. Under higher wear loads, the subsurface of the worn sample suffers more damage, and consequently, the subsurface matrix layer could not withstand the plowing stroke. The presence of carbon fibers during sliding reduces both friction and heat generation and then improves the wear resistance of the material. The material loss during the relative sliding motion between the bush and composite is accompanied by carbon fibers loss. Under shear load, the worn graphite tends to smear both the sample surface and the countersurface of the bush. The presence of a graphite film postpones the transition from mild to severe wear (Fig. 6). This finding is confirmed by previous works [26]. Carbon lubricating film is formed progressively on the sliding surface under the normal load of $3.14 \mathrm{~N}$ with high sliding distances. Formation of the graphite film during sliding limits direct metal-to-metal interactions between the composite surface and the hard steel bush. This reduces the level of shear component leading to less metal removal and finally decreases the wear rate (Fig. 7).

EDX analysis was conducted on the worn surface of the base Mg alloy AE42 under the wear conditions of $2.45 \mathrm{~N}$ wear load and $8.9 \mathrm{~km}$ sliding distance (Fig. 11). Results indicate that the precipitates are mainly $\mathrm{Mg}$ rich, as indicated during analysis of spot numbers from 2 to 4 , and $\mathrm{Mg}-$ $\mathrm{Al}$ in spot number 1 , since the solubility of $\mathrm{Al}$ in $\mathrm{Mg}$ at room temperature is very low (it reaches approximately $2 \mathrm{wt} \%)$ and it increases up to $12.7 \mathrm{wt} \%$ at $437^{\circ} \mathrm{C}[27,28]$.
Under the higher wear load of $4.9 \mathrm{~N}$ for the same sliding distance of $8.9 \mathrm{~km}$ (Fig. 12), oxygen and aluminum are detected. The presence of oxygen indicates formation of some oxides, which is mostly $\mathrm{MgO}$ [29]. However, AE42 is one of the most oxidation-resistant $\mathrm{Mg}$ alloys at high temperatures $\left(400,450\right.$, and $\left.500{ }^{\circ} \mathrm{C}\right)$ in comparison with other Mg alloys (AZ91, AM60, and AM50), as studied by Medved et al. [30]. $\mathrm{Mg}-\mathrm{Al}$ precipitates are mostly $\mathrm{Mg}_{17}$ $\mathrm{Al}_{12}$ types, which combine with approximately $0.7 \mathrm{wt} \% \mathrm{Al}$ [31]. The remainder of the aluminum either dissolves in the $\mathrm{Mg}$ matrix or combines with the RE elements [31]. The oxide leaves the surface easily in form of debris and then decreases the wear resistance. Therefore, oxidation is likely to be one of the dominant wear mechanisms at high loads for the Mg matrix alloy.

EDX analysis of the worn surface of the AE42-C composites under high wear load $4.9 \mathrm{~N}$ for $8.9 \mathrm{~km}$ is shown in Fig. 13, and the percentages of detected elements are listed in Table 4. In addition to the elements in matrix alloy AE42 at the same wear load $(4.9 \mathrm{~N})$, carbon is detected. Another difference is a lower amount of oxygen in composites than that detected in the matrix alloy. This reflects the influence of the graphite film generated by sliding wear of the carbon fibers. It is difficult to suppose that carbon is working here as a reducing agent; however, it can at least minimize matrix oxidation. Unlike what happened on reinforcing of Mg alloy AZ91 with $\mathrm{SiCp}$, which led to dominant oxidation mechanism [15]. Because of the lower oxidation tendency of the AE42-C composite than that detected in the matrix alloy, oxidation cannot be drawn to AE42-C composite as one of the wear mechanisms. 


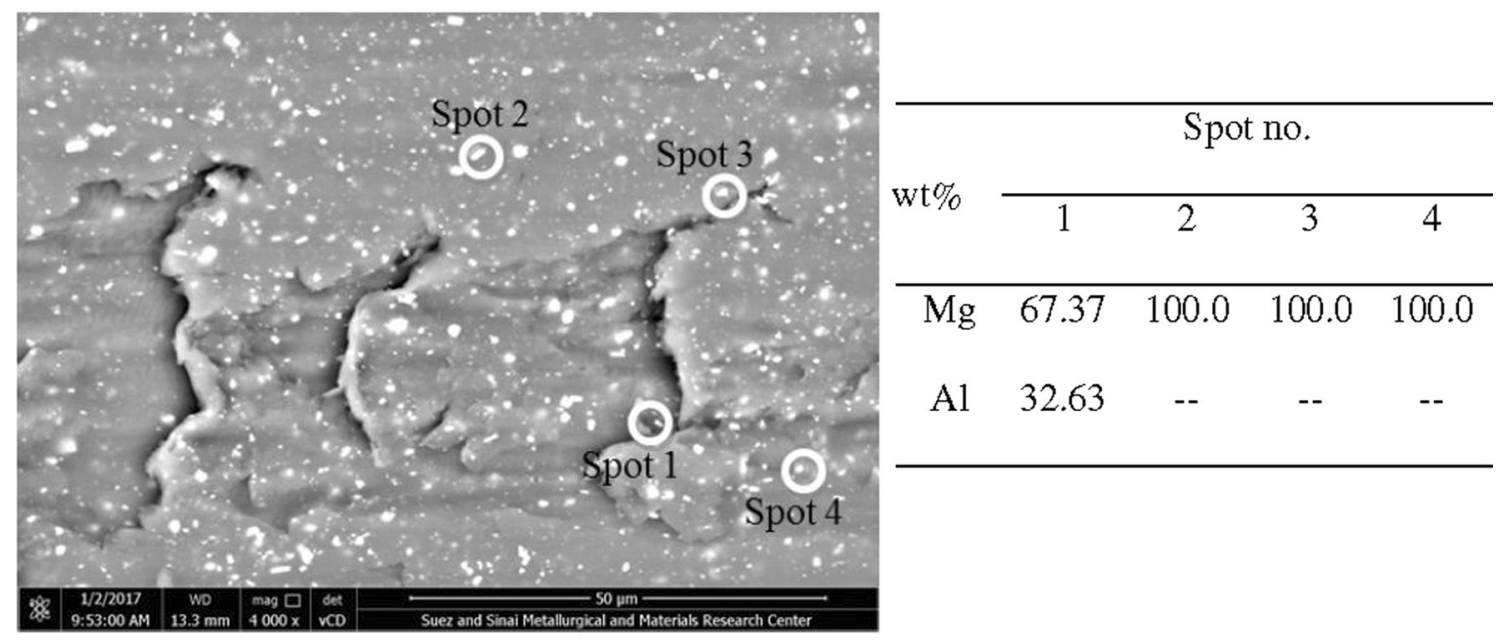

Fig. 11 EDX analysis of worn surface of AE42 under a wear load of $2.45 \mathrm{~N}$ for a sliding distance of $8.9 \mathrm{~km}$

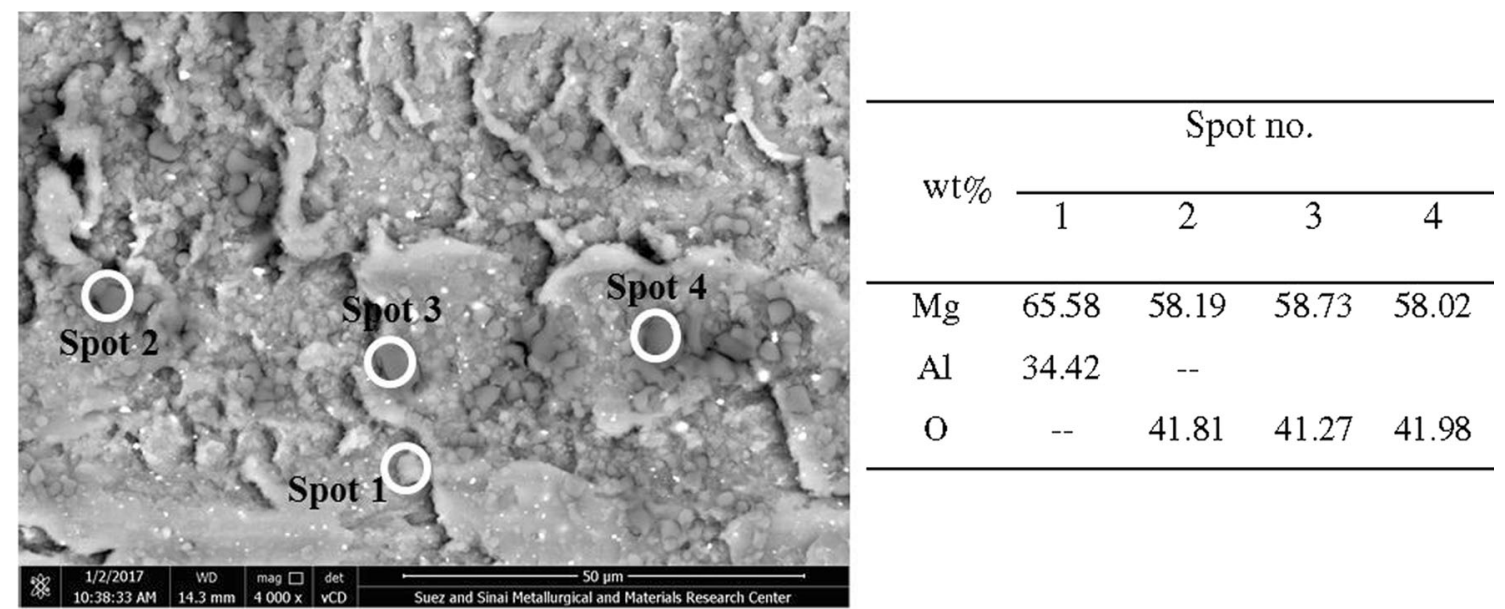

Fig. 12 EDX analysis of the worn surface of AE42 under a wear load of $4.9 \mathrm{~N}$ for a running distance of $8.9 \mathrm{~km}$

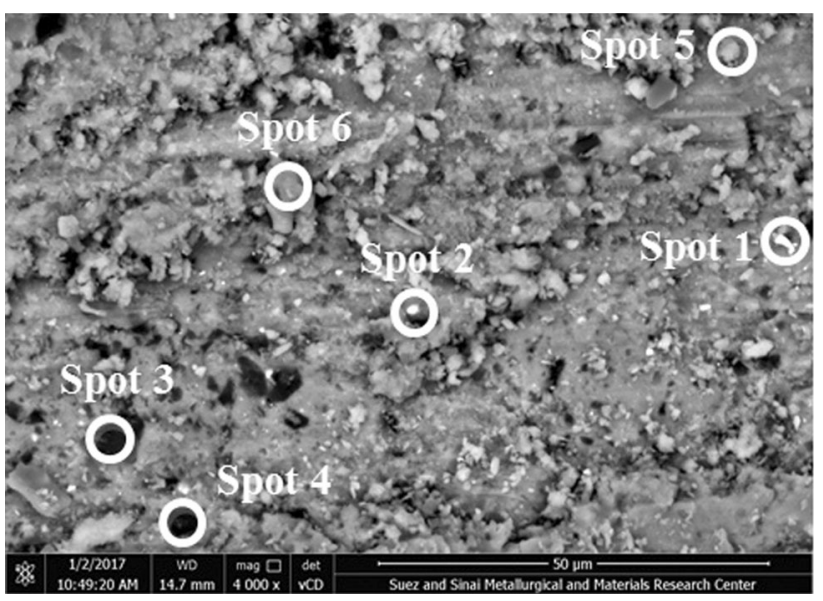

Fig. 13 EDX analysis of the worn surface of AE42-C composites under a load of $4.9 \mathrm{~N}$ for a wear distance of $8.9 \mathrm{~km}$

\section{Conclusions}

(1) Reinforcing of AE42 with 23 vol\% random graphite short fibers increases the hardness of AE42 alloy by $100 \%$ and significantly improves compressive strength at elevated temperatures of 150 and $200{ }^{\circ} \mathrm{C}$.

(2) The wear rate of AE42-C is remarkably decreases with the addition of $23 \mathrm{vol} \%$. Application of different loads at a constant sliding distance or application of different sliding distances at a constant load induces more weight loss of AE42 than AE42-C.

(3) The presence of graphite film on a worn surface improves the wear environment between the AE42-C composite and the moving steel bush. It is smearing to the area of contact which delays the change from mild to severe wear and then increases the wear resistance of AE42-C. 
Table 4 EDX analysis (wt \%) of various spots shown in the micrograph in Fig. 13 for AE42-C under wear load of $4.9 \mathrm{~N}$ for sliding distance of $8.9 \mathrm{~km}$

\begin{tabular}{lllllll}
\hline Elements (wt\%) & Spot 1 & Spot 2 & Spot 3 & Spot 4 & Spot 5 & Spot 6 \\
\hline $\mathrm{Mg}$ & 100.0 & 64.88 & - & 11.38 & 68.33 & 72.78 \\
$\mathrm{Al}$ & - & 12.59 & - & - & - & - \\
$\mathrm{O}$ & - & 22.53 & - & - & 31.67 & 27.22 \\
$\mathrm{C}$ & - & - & 100.0 & 88.62 & - & - \\
\hline
\end{tabular}

(4) EDX analysis of a worn surface suggests oxidation of the matrix alloy at higher wear load, which decreases in the presence of carbon fibers under the same wear load.

(5) Abrasive wear, oxidation, and plastic deformation are the primary working wear mechanisms for AE42, while abrasive wear is mainly the wear mechanism for AE42-C composite.

Acknowledgement The authors thank Dr. S. Mielke (Kolbenschmidt Company, Neckarsulm Germany) for helping with production of the materials under study.

\section{References}

[1] C. Fritze, H. Berek, K.U. Kainer, S. Mielke, B. Weilage, in Proceeding of Magnesium alloys and Their Applications, Wolfsburg, Germany, (1998), p. 635

[2] T. Tokunaga, M. Ohno, K. Matsuura, J. Mater. Sci. Technol. 34, 1119 (2018)

[3] J.W. Kaczmar, K. Pietrzak, W. Wlosinski, J. Mater. Process. Technol. 106, 58 (2000)

[4] Q.J. Qi, Trans. Nonferrous. Met. Soc. 16, 1135 (2006)

[5] X. Zhang, L. Fang, B. Xiong, H. Hu, J. Mater. Eng. Perform. 24, $4601(2015)$

[6] J. Shao, W. Li, R. Wang, Y. Tao, H. Kou, Y. Deng, X. Zhang, Y. Li, X. Wang, J. Mater. Sci. 60, 6065 (2018)

[7] M. Song, G. Wu, W. Yang, W. Jia, Z. Xiu, G. Chen, J. Mater. Sci. Technol. 26, 931 (2010)

[8] S. Ataya, E. El-Magd, Comput. Mater. Sci. 39, 155 (2007)

[9] S. Li, L. Qi, T. Zhang, J. Zhou, H. Li, J. Alloys Compd. 663, 686 (2016)

[10] S. Ataya, E. El-Magd, Theor. Appl. Fract. Mech. 47, 102 (2007)
[11] Y.D. Huang, N. Hor, H. Dieringa, P. Maier, K.U. Kainer, Int. J. Fatigue 28, 1399 (2006)

[12] G. Li, J. Zhang, R. Wu, Y. Feng, S. Liu, X. Wang, Y. Jiao, Q. Yang, J. Meng, J. Mater. Sci. Technol. 34, 1076 (2018)

[13] L.G. Hou, R.Z. Wu, X.D. Wang, J.H. Zhang, M.L. Zhang, A.P. Dong, B.D. Sun, J. Alloys Compd. 695, 2820 (2017)

[14] F. Labib, H.M. Ghasemi, R. Mahmudi, Wear 348, 69 (2016)

[15] K.K.A. Kumar, A. Viswanath, T.P.D. Rajan, U.T.S. Pillai, B.C. Pai, Acta Metall. Sin. (Engl. Lett.) 27, 295 (2014)

[16] Q.B. Nguyen, Y.H.M. Sim, M. Gupta, Y.H. Lim, Tribol. Int. 82, 464 (2015)

[17] S.T. Selvamani, S. Premkumar, M. Vigneshwar, P. Hariprasath, K. Palanikumar, J. Magnes. Alloy 5, 326 (2017)

[18] M.M. El-Sayed Seleman, M.M.Z. Ahmed, S. Ataya, J. Mater. Sci. Technol. (2018). https://doi.org/10.1016/j.jmst.2018.03.004

[19] A.K. Mondal, B.S.S.C. Rao, S. Kumar, Tribol. Int. 40, 290 (2007)

[20] A. Olszówka-Myalska, J. Myalski, Solid State Phenom. 229, 115 (2015)

[21] L. Chen, Y. Yao, Acta Metall. Sin. (Engl. Lett.) 27, 762 (2014)

[22] R.J. Diefendorf, Engineered Materials Handbook: Composites, vol. 1 (Russell Township, ASM International, 1988), pp. 49-53

[23] R. Askeland, The Science and Engineering of Materials, 3rd ed. (PWS Publishing Co., Boston, 1994)

[24] ASM Specialty Handbook, in Magnesium and Magnesium Alloys, ed. by M.M. Avedesian, H. Baker (ASM International, Metals Park, 1999)

[25] A.K. Mondal, S. Kumar, Wear 267, 458 (2009)

[26] J. Singh, Friction 4, 191 (2016)

[27] M.M. Islam, A.O. Mostafa, M. Medraj, J. Mater. 2014, 1 (2014)

[28] J.C. Liu, J. Hu, X.Y. Nie, H.X. Li, Q. Du, J.S. Zhang, L.Z. Zhuang, Mater. Sci. Eng. A 635, 70 (2015)

[29] Q. Tan, A. Atrens, N. Mo, M. Zhang, Corros. Sci. 112, 734 (2016)

[30] J. Medved, P. Mrvar, M. Vončina, Oxid. Met. 71, 257 (2009)

[31] Y.D. Huang, H. Dieringa, N. Hort, P. Maier, K.U. Kainer, L.U. Liu, J. Alloys Compd. 463, 238 (2008) 